\title{
Numerical Investigation of Forced Convection Heat Transfer from Longitudinal Perforated Fins in a Horizontal Rectangular Channel
}

\author{
Eng: Alyaa Q.Najm ${ }^{1} \quad$ Prof: Saadoon F. Dakhil ${ }^{1} \quad$ Assist Prof: Falah A.Abood ${ }^{2}$ \\ 1.Basrah Engineering Technical College/Southern Technical University-Basra-Iraq \\ 2.Mechanical Engineering Department/ Engineering College - Basra -Baghdad-Iraq
}

\begin{abstract}
The present paper reports a numerical study to investigate the heat transfer enhancement over horizontal channel with longitudinal rectangular fin arrays by laminar forced convection heat transfer. Fins are perforated with two types of holes, square and circular with different diameters. Three-dimensional steady-state continuity, momentum and energy equations along with the Boussinesq approximation were solved by finite volume method with commercial available software ANSYS FLUENT 15.1. The bottom finned wall of the channel was supplied with constant heat flux, while the other sides are insulated. Data used in performance analysis were obtained numerically for fin arrays of material aluminum, by varying geometry, diameter and number of perforation (12, 16 and 20$) \mathrm{mm},(10-22)$ respectively. In addition at different channel inclinations $\left(0^{\circ}, 90^{\circ}\right.$ and $\left.180^{\circ}\right)$, as well as by varying Reynolds number from 1800 to 2300, at modified Grashof number $\mathrm{Gr}^{*} 5 \times 10^{8}$. The results show that the Reynolds number and size perforation have a larger impact on average heat transfer coefficients for the both type of Perforations. Also the channel inclination increases the removal heat from the channel.
\end{abstract}

Keywords: Force convection, heat transfer, perforated fin arrays, square holes, notch fins, ordination angle.

DOI: $10.7176 /$ JNSR/9-16-05

Publication date: August $31^{\text {st }} 2019$

\section{1-Introduction:}

It is necessary to enhances heat transfer removal in engineering systems because these systems generate heat during their operation. If this generated heat is not dissipating rapidly to its surrounding atmosphere, this may cause rise in temperature of the system components and then failure. This byproduct cause serious overheating problems in system and leads to system failure, so the generated heat within the system must be rejected to its surrounding to maintain the system at recommended temperature for its efficient working [1]. There are different methods to enhancement heat depended on the application and required work (cooling/heating) such as increase area by adding fins or different shape cavities, Nano fluid, swirl etc. [2]. Fins are extensively considered as the main method of heat transfer for heated surfaces to the environment to avoid the burning or overheating of the system. The use of extended surfaces is of practical importance for numerous applications such as cooling the Air-cooled engine cylinder head, Economizers for steam power plants, Radiators of automobiles etc. [3]. To dissipate more heat from these fins a large number of studies has been introduced on the shape modifications by cutting some material from fins to make cavities, holes, slots, grooves, or channels through the fin body [4]. Utilization of perforated fins increases thermal performance of arrays, simultaneously reduction in fins weight, low weight means saving material of fin and which decreases the expenditure on the fin material and related equipment. In flow friction factor of the perforated fin arrays inside the duct more than the arrays of solid fins, it may be due to turbulence and resistance against flow because of perforation. As result the pressure drops over the test section with the perforated fin arrays. Friction factor slightly increases with increase in the size of perforation [5]. The objective of the present work is to study theoretically the effect of fins perforation and its perforation size and shape. Also, study the effect of finned wall inclination on heat tansfer with different rate of the air mass flow.

\section{Nomenclature}

$A_{c}$ : Channel cross sectionarea (m2)

$H_{f}$ : Fin height $(\mathrm{m})$

$w_{\text {in }}$ : Mean longitudinal velocity $(\mathrm{m} / \mathrm{s})$

$K_{a}$ : Thermal conductivity of air $(\mathrm{W} / \mathrm{m} \mathrm{K})$

$T_{\text {in }}$ : Inlet air Temperature $\left({ }^{\circ} \mathrm{C}\right)$

$T_{\text {out }}$ : Outlet air Temperature $\left({ }^{\circ} \mathrm{C}\right)$

$D_{\mathrm{h}}$ : Hydraulic diameter of the duct (m)

$h_{\mathrm{av}}$ : Average Heat transfer coefficient $\left(\mathrm{W} / \mathrm{m}^{2} . \mathrm{K}\right)$

$\varepsilon_{f}$ : Overall effectiveness of fin arrays

$\mathrm{t}$ : Thickness of fin (m)

$L_{f}$ : Length of fin (m)

P: perimeter $(\mathrm{m})$

$N_{p}$ : Number of perforations

$q^{\prime \prime}$ : Convection heat flux $\left(\mathrm{W} / \mathrm{m}^{2}\right)$

S: Fin spacing $(\mathrm{m})$

Re : Reynolds number

Gr*: Modified Grashof number

$n$ : Number of fin 


\section{Greek Symbols}

$v$ : Kinematic viscosity of air $\left(\mathrm{m}^{2} / \mathrm{s}\right)$

$\beta$ : Thermal expansion coefficient $(1 / \mathrm{k})$

\section{3- Model Description and Assumptions}

A schematic drawing of the fin array under force convection heat transfer and computational domain used for numerical is shown in Fig.1. The problem analyzed includes convection heat transfer inside a duct have a dimensions $150 \times 28.5 \times 10 \mathrm{~cm}$ where the unheated inlet zone of the duct is $60 \mathrm{~cm}$ while the outlet unheated zone is $30 \mathrm{~cm}$. The length of the test section is $60 \mathrm{~cm}$ which subjected to a constant heat flux at the bottom wall and contact to 15 longitudinal fins of $2 \mathrm{~mm}$ thickness, $60 \mathrm{~cm}$ height and spacing of $17 \mathrm{~mm}$.It is assumed that holes are drilled as one row for $60 \mathrm{~cm}$ height with three different size of holes (12, 16 and 20) $\mathrm{mm}$ in addition to different holes number (10 and 22) as shown in table 1. A schematic diagram of the fin arrays are given at Fig.2.

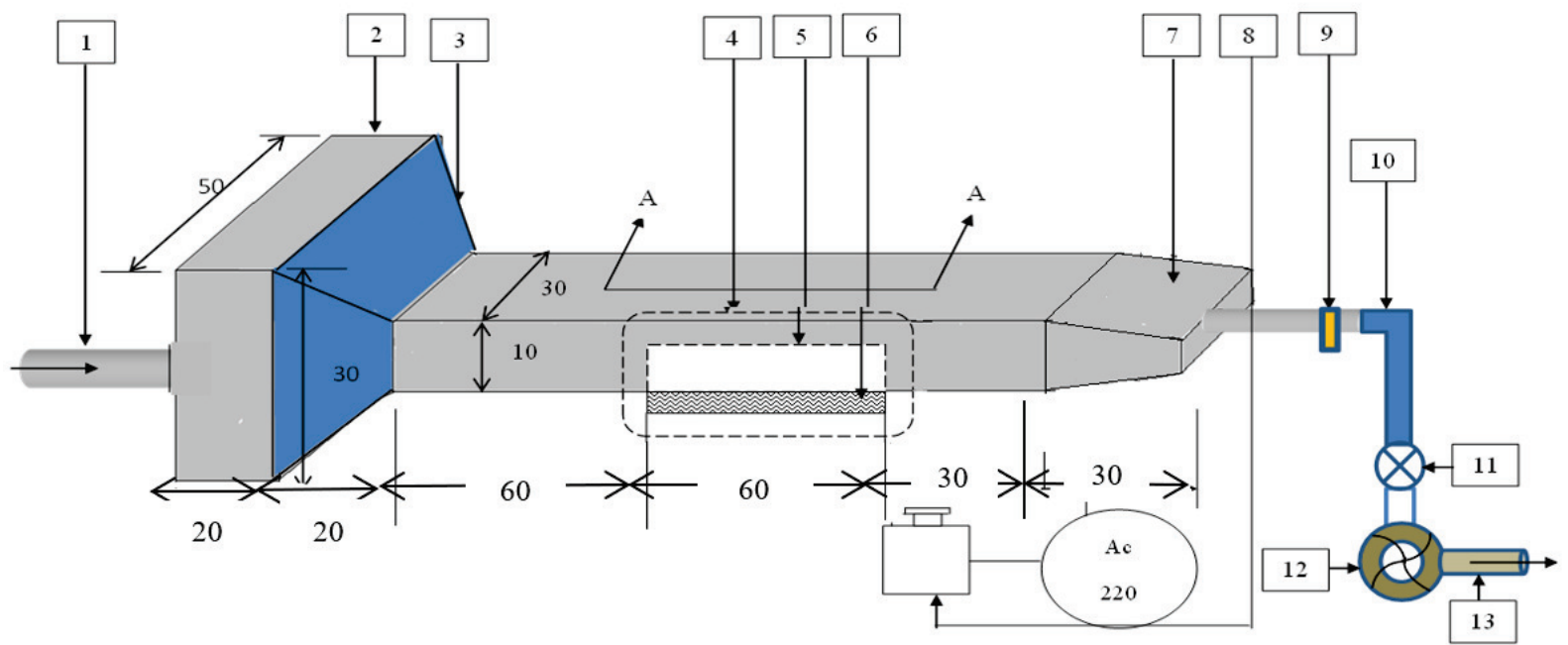

1- Inlet air 2-Damping Chamber 3-Inlet Nozzle 4- Test section 5-Fin 6-Surface Heat Source 7- Out Nozzle 8-Variac 9- air flowmetere 10-flexibl hose 11-valve 12-fan 13-air outlet

Figure 1. Diagram of the rig

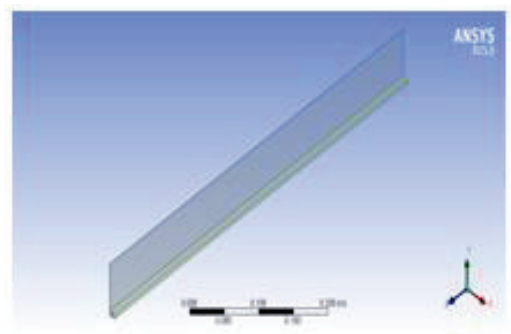

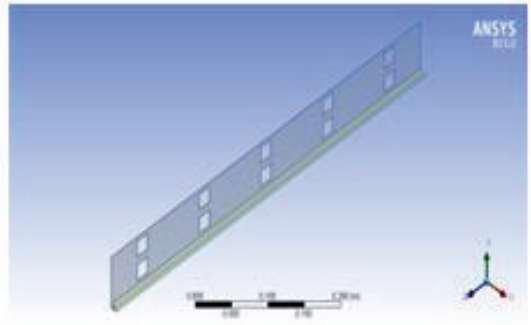

(b) Square perforation

Figure 2. A schematic of the fin arrays

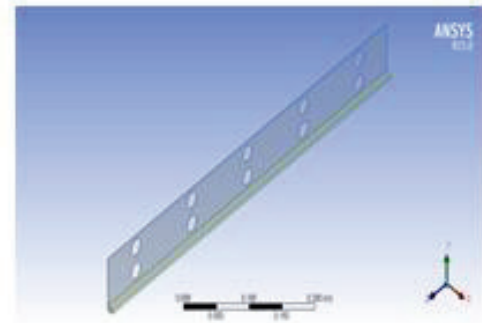

(c) Circular perf
(a)Solid fin 


\begin{tabular}{|l|l|c|c|c|}
\hline Types of fin & $\begin{array}{l}\text { Size of fin } \\
(\mathrm{L} \times \mathrm{H} \times \mathrm{t}) \\
\mathrm{mm}\end{array}$ & $\begin{array}{l}\text { Size of } \\
\text { perforation } \\
\text { in }(\mathrm{mm})\end{array}$ & \multicolumn{2}{|l|}{ No. of perforation } \\
\hline Solid fin & $600 \times 60 \times 2$ & - & \multicolumn{2}{|l|}{} \\
\hline $\begin{array}{l}\text { Square } \\
\text { perforation }\end{array}$ & $600 \times 60 \times 2$ & 16 & 10 & 22 \\
\cline { 3 - 5 } & & 12 & 10 & 22 \\
\hline \multirow{2}{*}{$\begin{array}{l}\text { Pircular } \\
\text { perforation }\end{array}$} & $600 \times 60 \times 2$ & 20 & 10 & 22 \\
\cline { 3 - 5 } & & 16 & 10 & 22 \\
\cline { 3 - 5 } & & 12 & 10 & 22 \\
\hline
\end{tabular}

Table 1. Geometry of various types fin arrays studied.

Since all fins are symmetric and geometrical identical, the boundary conditions also take the same flow rate and heat flux, so the calculation domain can be limited to unit volume involve one half channel $(S / 2)$ and one half fin $\left(t_{f} / 2\right)$ as shown in Fig.3.

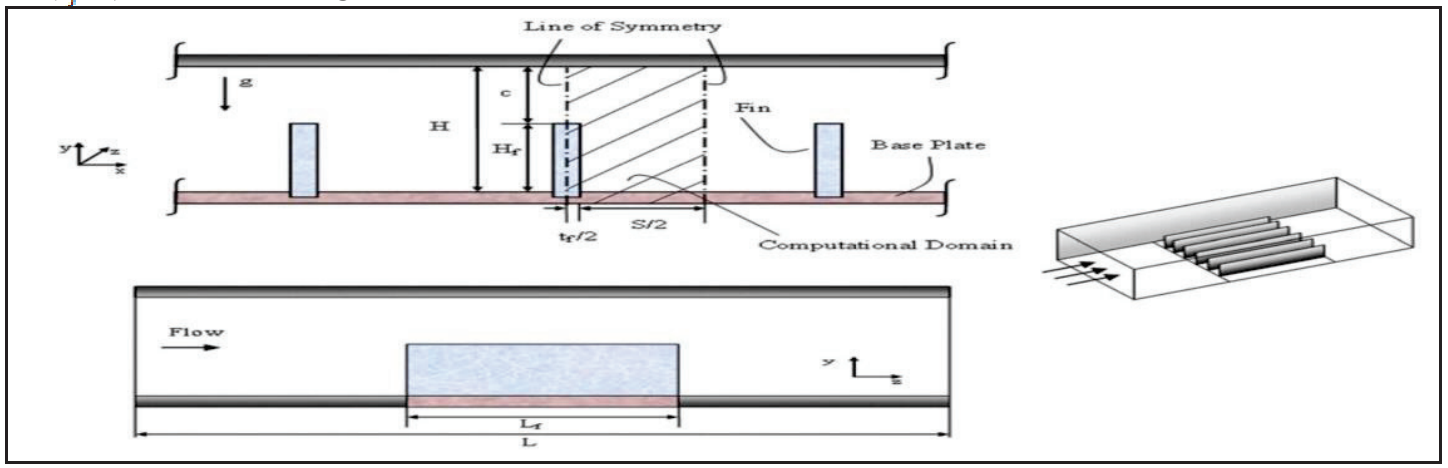

Figure 3. Schematic drawing of fin array and computational domain.

The following assumptions are used in the present model solution:

- The fluid is assumed to be Newtonian,

- The flow is assumed to be steady, laminar, 3D incompressible flow and the flow enters the duct with uniform velocity.

- $\quad$ The working fluid is air with constant properties.

- Ignored viscous dissipation term and radiation in the energy equation, also there is no internal heat generation.

- All solid boundaries are to be rigid no-slip condition.

\section{4-CFD Models}

Computational fluid dynamics (CFD) is one of the branches of fluid mechanics that uses numerical methods and algorithms to solve and analyze problems that involve fluid flows. The numerical solver codes are wellestablished and thus provide a good start to more complex heat transfer and fluid flow problems. FLUENT provides adaptability to variation of thermo physical properties with respect to temperature effect. The fundamental basis of any CFD Computational fluid dynamics (CFD) is one of the branches of fluid mechanics that uses numerical methods and algorithms to solve and analyze problems that involve fluid flows. The numerical solver codes are well-established and thus provide a good start to more complex heat transfer and fluid flow problems. FLUENT provides adaptability to variation of thermo physical properties with respect to temperature effect. The fundamental basis of any CFD problem is the Navier-Stokes equations, which define any single-phase fluid flow. These equations can be simplified by removing terms describing viscosity to yield the Euler equations. Further simplification, by removing terms describing vorticity yields the full potential equations. Finally, these equations can be linearized to yield the linearized potential equations.

Thus the equations for mass, momentum and energy conservation of 3D, steady, laminar and incompressible flow considered in this study are as follows [6]. 


\section{Continuity equation:}

$\frac{\partial u}{\partial x}+\frac{\partial v}{\partial y}+\frac{\partial w}{\partial z}=0$ 1

$\mathrm{X}$ - Direction momentum equation:

$u \frac{\partial u}{\partial x}+v \frac{\partial u}{\partial y}+w \frac{\partial u}{\partial z}=v\left(\frac{\partial^{2} u}{\partial x^{2}}+\frac{\partial^{2} u}{\partial y^{2}}+\frac{\partial^{2} u}{\partial z^{2}}\right)-\frac{1}{\rho} \frac{\partial p}{\partial x}$

Y-Direction momentum equation:

$u \frac{\partial v}{\partial x}+v \frac{\partial v}{\partial y}+w \frac{\partial v}{\partial z}=v\left(\frac{\partial^{2} v}{\partial x^{2}}+\frac{\partial^{2} v}{\partial y^{2}}+\frac{\partial^{2} v}{\partial z^{2}}\right)-\frac{1}{\rho} \frac{\partial p}{\partial y}+\beta g\left(T-T_{0}\right) \ldots$

Z- Direction momentum equation:

$u \frac{\partial w}{\partial x}+v \frac{\partial w}{\partial y}+w \frac{\partial w}{\partial z}=v\left(\frac{\partial^{2} w}{\partial x^{2}}+\frac{\partial^{2} w}{\partial y^{2}}+\frac{\partial^{2} w}{\partial z^{2}}\right)-\frac{1}{\rho} \frac{\partial p}{\partial z}+\beta g\left(T-T_{0}\right) \cos \theta \ldots 4$

Energy equation:

$u \frac{\partial T_{f}}{\partial x}+v \frac{\partial T_{f}}{\partial y}+w \frac{\partial T_{f}}{\partial z}=\alpha\left(\frac{\partial^{2} T_{f}}{\partial x^{2}}+\frac{\partial^{2} T_{f}}{\partial y^{2}}+\frac{\partial^{2} T_{f}}{\partial z^{2}}\right)$

Heat conduction equation governed the heated plate and fin:

$\frac{\partial^{2} T_{s}}{\partial x^{2}}+\frac{\partial^{2} T_{s}}{\partial y^{2}}+\frac{\partial^{2} T_{s}}{\partial z^{2}}=0$

The data will henceforth be represented using the following non-dimensional parameters.

i-The Reynolds number:

$R e=\frac{w_{\text {in }} D_{h}}{v_{\text {air }}}$

ii-The modified Grashof number $\mathrm{Gr}^{*}$ :

$G r^{*}=\frac{g \beta q_{\text {con }}^{\prime \prime} D_{h}{ }^{4}}{k_{\text {air }} v_{\text {air }}{ }^{2}}$

$D_{h}=\frac{4 A_{c}}{P_{c}}$

iii- average heat transfer coefficients :

$h_{a v}=\frac{q_{\text {con }}^{\prime \prime}}{\left(T_{w_{a v}}-\frac{T_{\text {in }}+T_{\text {out }}}{2}\right)}$

iv- Overall effectiveness of fin arrays

$\varepsilon_{f}=\frac{n\left(Q_{u n f i n}+Q_{\text {fin }}\right)}{Q_{\text {nofin }}}$

Where: $\left(w_{\text {in }}\right),\left(v_{\mathrm{f}}\right)$ and $\left(\mathrm{D}_{\mathrm{h}}\right)$ are inlet air velocity of unheated channel $(\mathrm{m} / \mathrm{s})$, the kinematics viscosity of fluid $\left(\mathrm{m}^{2} / \mathrm{s}\right)$ and hydraulic diameter $(\mathrm{m})$ respectively. $\left(A_{c}\right)$ and $\left(P_{c}\right)$ are channel cross section area $\left(\mathrm{m}^{2}\right)$ and perimeter of the channel $(m)$ respectively.

During determination, the ambient temperature $T_{0}$ was selected as $T_{0}=T_{i n}=296^{\circ} \mathrm{k}$. The fluid properties are calculated at this temperature.

\section{1- Boundary condition}

Due to symmetry conditions, it has been only one of the fin channel is considered to produce an analysis of computational domain and boundaries system are presented as in Fig.3. The conduction equation is applied in the wall involving of the fin and the base plate. The other surface top wall, the unheated entrance region and the exit region are insulated. On other hand, no slip condition was applied along all solid walls and the flow velocities on these walls were set to zero. The constant heat flux is applied at the base plate. At the planes of symmetry is applied symmetry boundary condition. However, based on the Fig.4 and previous assumptions, the non-dimensional boundary conditions are shown in Table (2) 


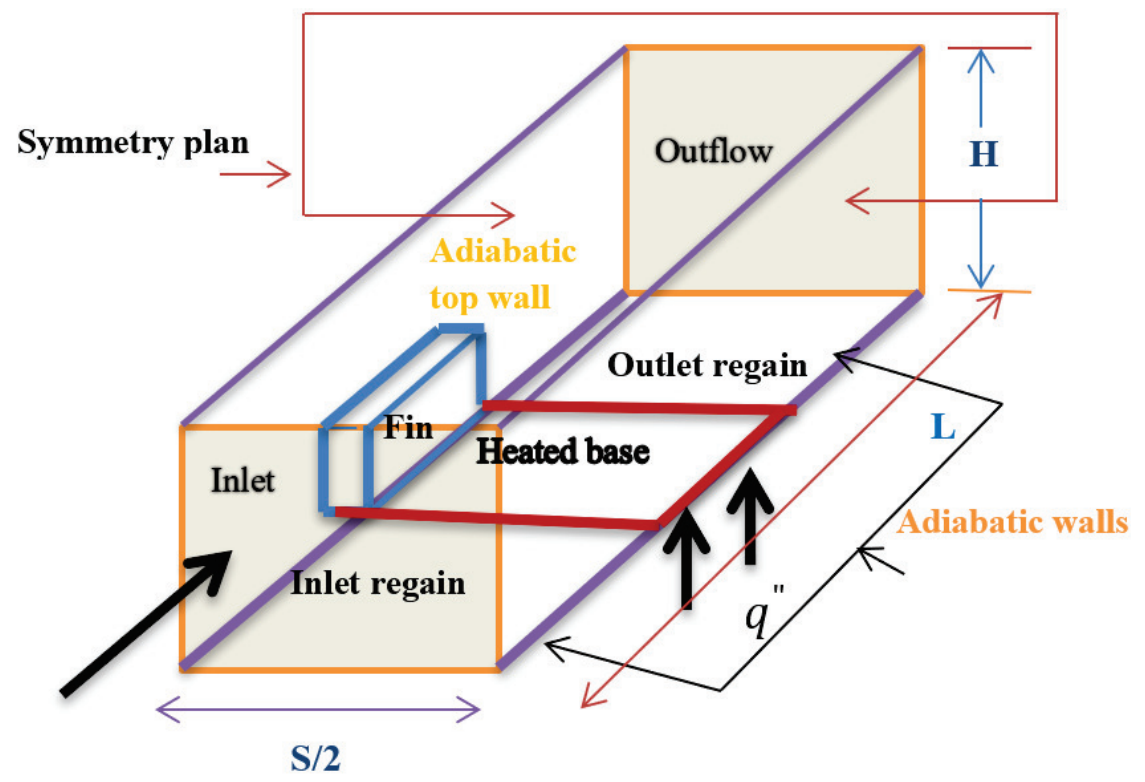

Figure 4. Schematic drawingof the computational domain shown the boundary condition applied at each location.

Table 2. Boundary conditions

\begin{tabular}{|c|c|c|}
\hline Location & B.C & Comments \\
\hline At inlet & $v=u=0, \quad w=w_{\text {in }}, \quad \mathrm{T}_{\mathrm{f}}=\mathrm{T}_{\mathrm{in}}$ & $\begin{array}{l}\text { Velocity and temperature } \\
\text { condition }\end{array}$ \\
\hline At outlet & $\frac{\partial u}{\partial z}=0, \frac{\partial v}{\partial z}=0, \frac{\partial w}{\partial z}=0, \frac{\partial \mathrm{Tf}}{\partial z}=0$ & Outflow condition \\
\hline $\begin{array}{l}\text { At the symmetry } \\
\text { axis }\end{array}$ & $\begin{array}{l}\frac{\partial u}{\partial x}=0, \frac{\partial v}{\partial x}=0, \frac{\partial w}{\partial x}=0, \frac{\partial \mathrm{Tf}}{\partial x}=0 \\
\frac{\partial \mathrm{Ts}}{\partial x}=0\end{array}$ & Symmetry condition \\
\hline $\begin{array}{l}\text { At heated bottom } \\
\text { surface }\end{array}$ & $\mathrm{q}^{=}=-\mathrm{k}_{\mathrm{s}} \frac{\partial \mathrm{Ts}}{\partial y}$ & $\begin{array}{l}\text { Constant heat flux condition } \\
\left(\mathrm{w} / \mathrm{m}^{2}\right)\end{array}$ \\
\hline $\begin{array}{l}\text { Points of solid- } \\
\text { fluid contact } \\
\text { interface }\end{array}$ & $\mathrm{k}_{\mathrm{s}} \frac{\partial \mathrm{Ts}}{\partial n}=\mathrm{k}_{\mathrm{f}} \frac{\partial \mathrm{Tf}}{\partial n} \quad$ and $\quad \mathrm{T}_{\mathrm{s}}=\mathrm{T}_{\mathrm{f}}$ & $\begin{array}{l}\text { Where, } \mathrm{k}_{\mathrm{s}} \text { and } \mathrm{k}_{\mathrm{f}} \text { are thermal } \\
\text { conductivity of solid wall and } \\
\text { air respectively }(\mathrm{w} / \mathrm{m} . \mathrm{k})\end{array}$ \\
\hline
\end{tabular}

\section{4-2- Simulation}

Design modeler software able to draw the simple and complex geometries. In solver settings choose 3D, Segregated, steady and used standard Method for Pressure. Convective terms in momentum and energy equations are discretized using second order upwind interpolation scheme. SIMPLE algorithm with pressure velocity coupling and standard is adopted for pressure interpolation. Under- relaxation factors for pressure, density, body force, momentum and energy are equal to [0.3, 1, 1, 0.7 and 1] respectively. The calculations are performed using default commercial CFD code in ANSYS FLUENT 15.1.convergance criteria of 1E-5 for momentum equations and 1E-6 for energy equation. The simulation was performed with 8GB RAM Intel Core i7 processor.

\section{5-Results \& Discussions}

The important results are presented to show the effects of Reynolds number on the expected result with different channel inclination angle. Also the effect of shape, size and numbers of perforated holes inside fins are examined.

Figures [5.6 and 7], display the streamline and temperature distribution for different fin geometry, two shape (square and circular) of perforated as well as solid fin are chosen for this purpose as shown in Fig.1, and the corresponding values of Reynolds number $\mathrm{Re}=2000, \mathrm{Gr}^{*}=5 * 10^{8}, \mathrm{~S}=17 \mathrm{~mm}, \mathrm{x}=0.0125 \mathrm{~m}$ at perforations size $20 \mathrm{~mm}$ and perforations number 10 .

It is clear from the present figures that the fins geometry designing are influenced the heat performance and fluid flow. In addition the design of fins changes the flow path and its intensity. Evident change in air flow 
appears through the perforated fin. The results show that the intensity of the flow in the square holes more than that of a solid fin as illustrated in Figure (5).

It is noticed that the fluid close to the fins reaches to the maximum temperature. The conduction heat transfer occurs from bottom of a hot plate to the fins then the convection heat transfer take places from fins to the fluid. The air temperature increasing due to temperature difference between the fin and the air drops in downstream direction, so the air receives heat from fins and leads to increasing air temperature. Results showed that the heat transfer rates from a perforated fin are higher than the solid fin. This may be due to the availability of the larger heat transfer area as a result of existing of perforation. Evident change in air flow Temperature appears through the perforated fin. Temperature variation were appears through the thermal boundary layers. Where, the low temperature appears at the circular thermal boundary layer. As area removed from the fin is compensated at the air entry ends of the fin, it provides chance to get greater amount of fresh cold air to come in contact with hot fin surfaces. As shown in Fig.(6 and 7).
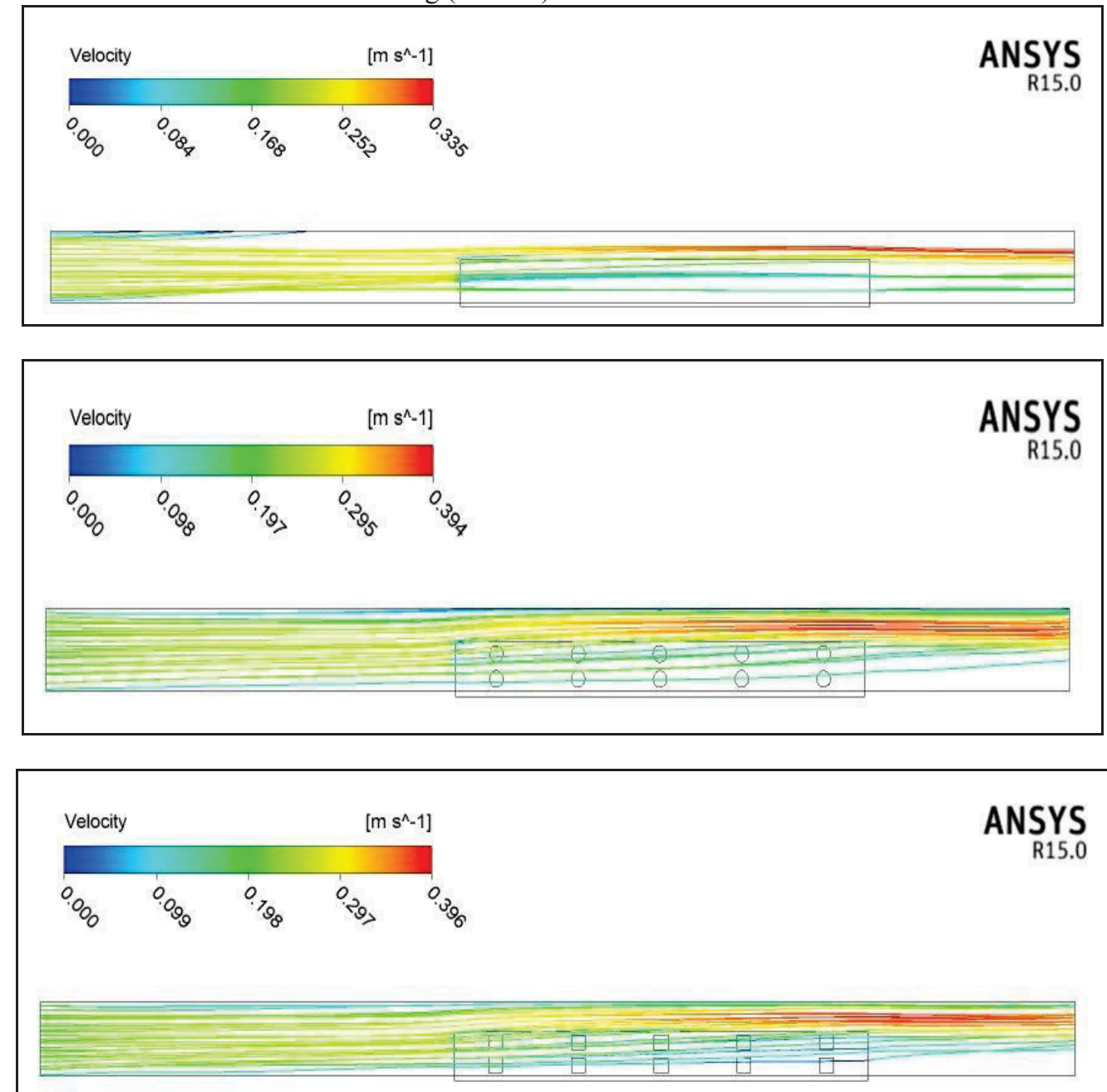

Figure 5. Comparison streamlines contour for circular, square and solid perforated rectangular fin $\mathrm{Gr}^{*}=5 * 10^{8}$, $\mathrm{Re}=2000, \mathrm{~S}=17 \mathrm{~mm} \mathrm{H}_{\text {fin }}=60 \mathrm{~mm}$, size of perforation $=20 \mathrm{~mm}$ at $\mathrm{x}=0.0125 \mathrm{~m}$ in $\mathrm{y}-\mathrm{z}$ plane 

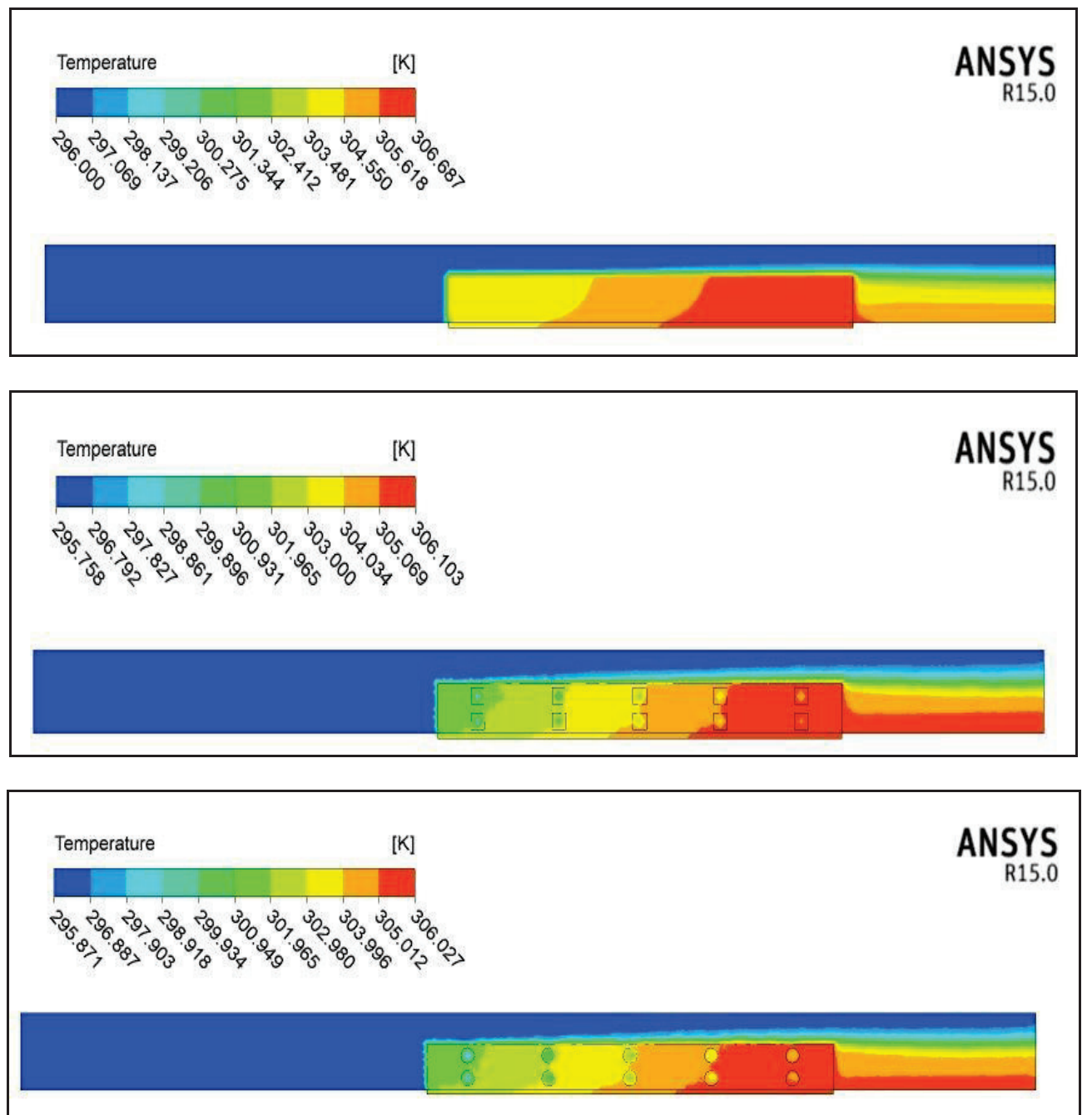

Figure 6. Temperature distribution for circular, square and solid perforated rectangular fin $\mathrm{Re}=2000$, $\mathrm{Gr}^{*}=5 \times 10^{8}, \mathrm{~S}=17 \mathrm{~mm} \mathrm{H}_{\text {fin }}=60 \mathrm{~mm}$, size of perforation $=20 \mathrm{~mm}$ at $\mathrm{x}=0.0125 \mathrm{~m}$
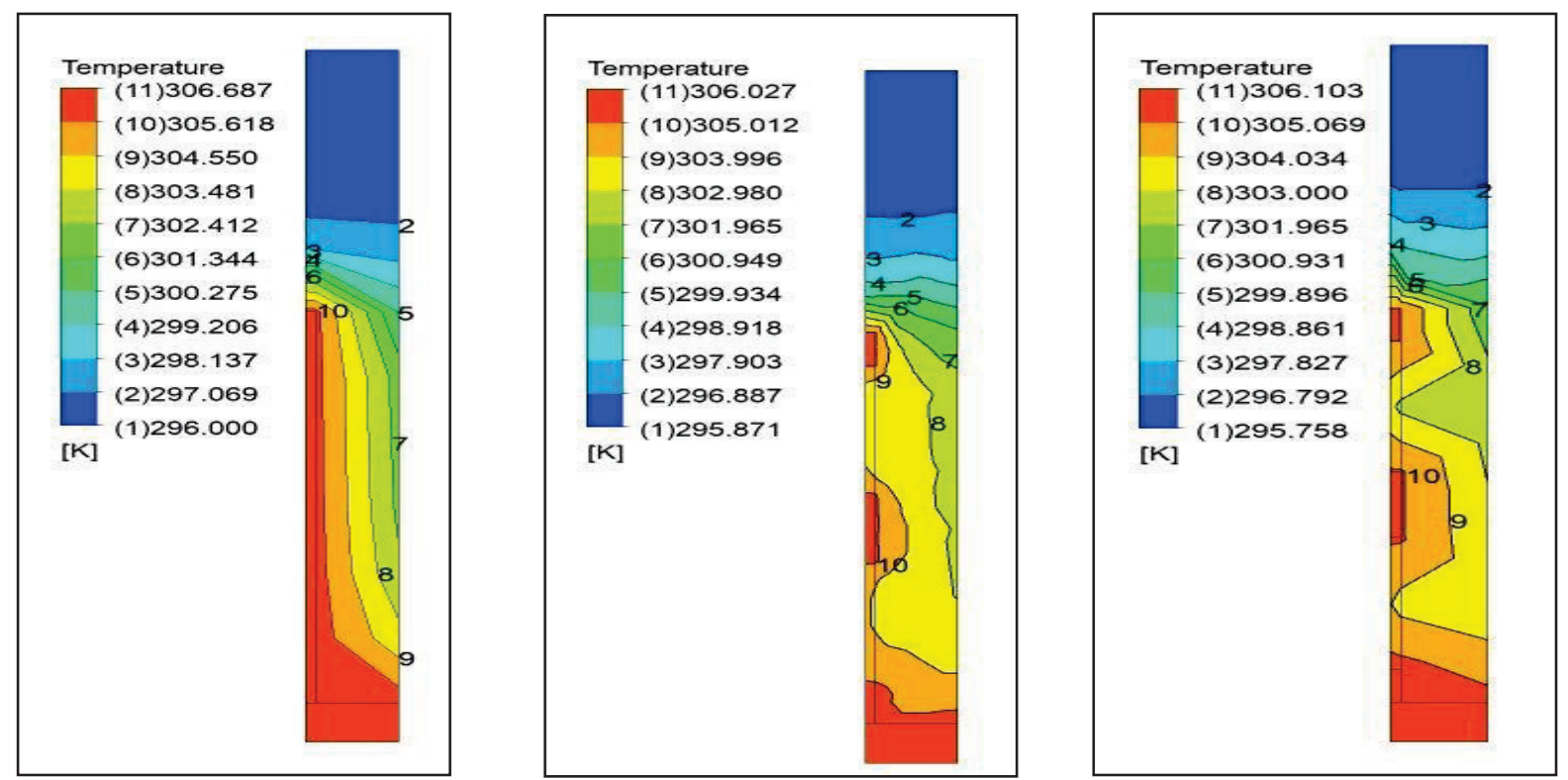

Figure 7. Temperature distribution for solid, circular and square perforated rectangular fin $\mathrm{Gr}^{*}=5 * 10^{8}, \mathrm{Re}=2000$, $\mathrm{S}=17 \mathrm{~mm} \mathrm{H} \mathrm{H}_{\text {fin }}=60 \mathrm{~mm}$, size of perforations $20 \mathrm{~mm}$, at $\mathrm{z}=1 \mathrm{~m}$ in $\mathrm{y}-\mathrm{x}$ plane. 
Fig.(8) Is illustrated the effect of perforated fin numbers for two shape (square and circular) on the average heat transfer coefficient of the moving fluid at different Reynolds number. Results show the comparisons between shape and numbers of holes with different Reynolds number (1800-2300) at fixed size of holes (16) mm. For the circular shape with $n_{p}=10$, indicates high removal heat than others due to enhance at flow circulation.

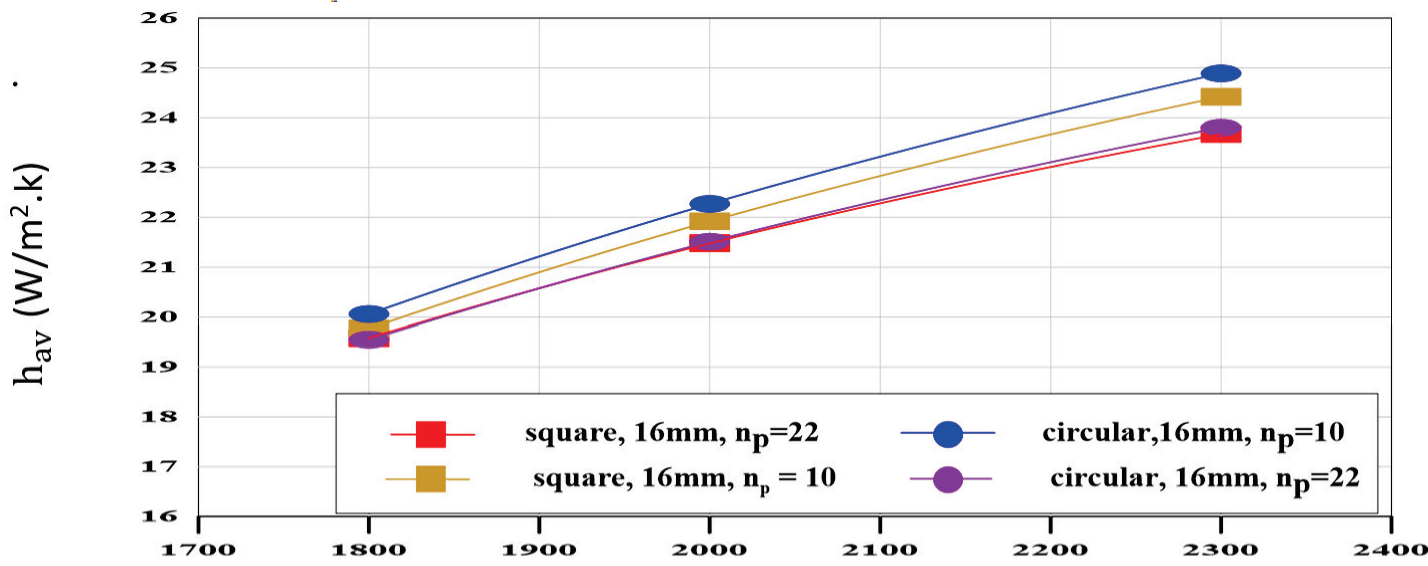

$\operatorname{Re}$

Figure 8.Temperature distribution for circular and square perforated rectangular fin at $\mathrm{Gr}^{*}=5 \times 10^{8}, \mathrm{~S}=17 \mathrm{~mm}$ and $\mathrm{H}_{\text {fin }}=60 \mathrm{~mm}$, perforated size $=16 \mathrm{~mm}$.

Fig. (9) And Fig.(10) are explained, the comparison of both inclination $\left(0^{\circ}, 90^{\circ}\right.$ and $\left.180^{\circ}\right)$ and size of perforated shape (square and circular) at constant $\mathrm{Gr}^{*}=5 \times 10^{8}, \mathrm{~S}=17 \mathrm{~mm}, \mathrm{H}_{\mathrm{fin}}=60 \mathrm{~mm}$ and $n_{p}=10$, as well as by varying Reynolds number from 1800 to 2300 . Results illustrate the effect above parameters on the average heat transfer coefficient. The results show high average heat transfer coefficient thus the channel inclination increases the removal heat from the channel. With square perforated fins and $16 \mathrm{~mm}$ dia at all flow rate, i.e reach $24.5 \mathrm{w} / \mathrm{m}^{2} \mathrm{~K}$ at $\mathrm{Re} 2300$. While, the circular perforated fins and $16 \mathrm{~mm}$ size at all flow rate, i.e reach $25\left(\mathrm{w} / \mathrm{m}^{2} . \mathrm{K}\right)$ at $\operatorname{Re} 2300$

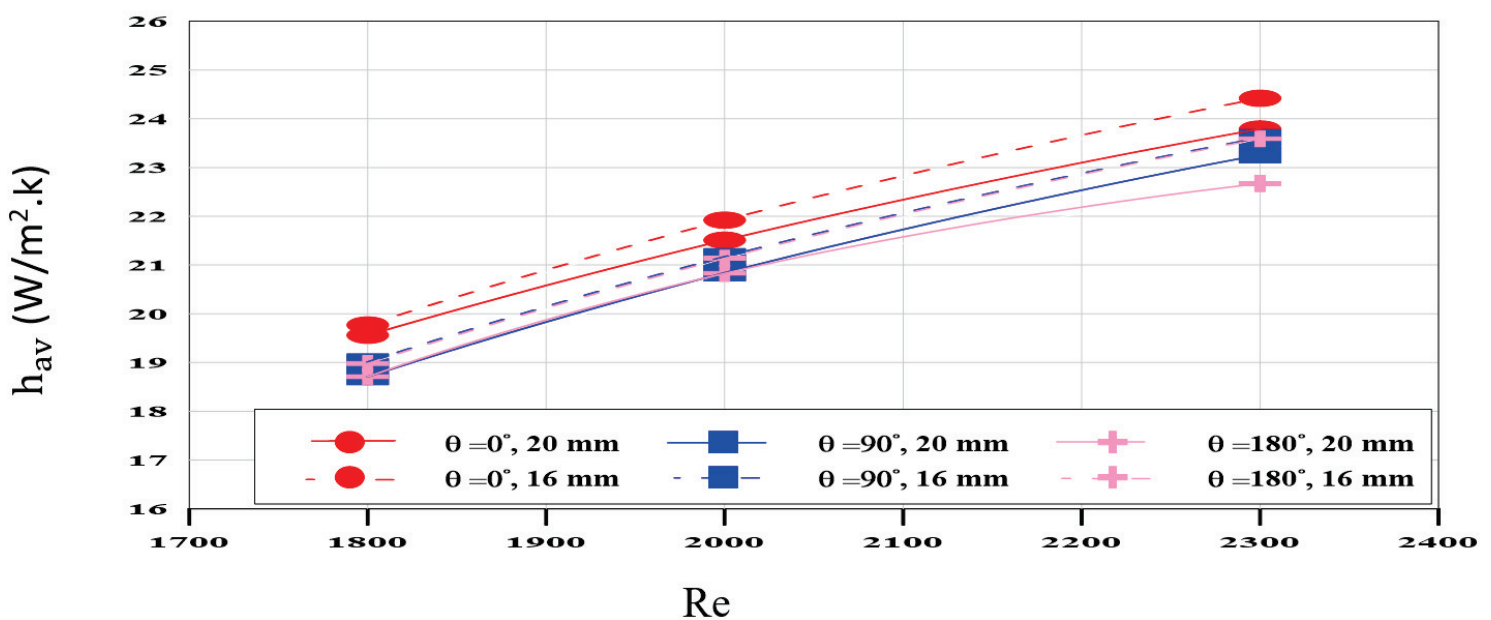

Figure 9. Distribution of average heat transfer coefficient for square perforated rectangular fin at $\mathrm{Gr}^{*}=5 * 10^{8}$, $\mathrm{S}=17 \mathrm{~mm}, \mathrm{H}_{\text {fin }}=60 \mathrm{~mm}$, with different wall inclination angle, and $n_{p}=10$. 


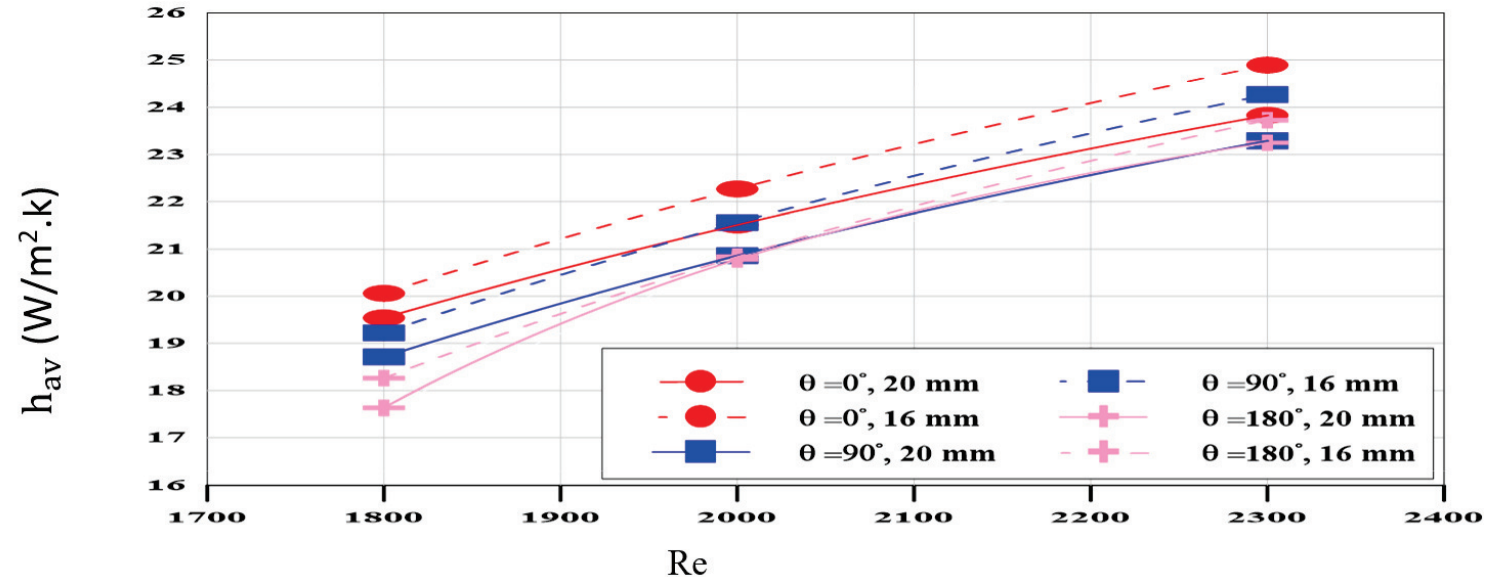

Figure 10. Distribution of average heat transfer coefficient for circular perforated rectangular fin at $\mathrm{Gr}^{*}=5 * 10^{8}$, $\mathrm{S}=17 \mathrm{~mm}, \mathrm{H}_{\mathrm{fin}}=60 \mathrm{~mm}$, with different wall inclination angle and different size, and $n_{p}=10$.

It is required to find out fin performance for different size of perforation for evaluating the effectiveness of new lateral perforation fin arrays. Fig.(11) are illustrate the variation of effectiveness of fin arrays with Reynolds number for different size and shape of perforation. It shows that the as Reynolds number increases, fin effectiveness of the fin arrays decreases for all types of fin arrays. The effectiveness of fins $\left(\varepsilon_{f}\right)$ are higher than (2)[8] for all type fin arrays. This means that the use of fin arrays leads to an advantage on the basis of heat transfer enhancement.

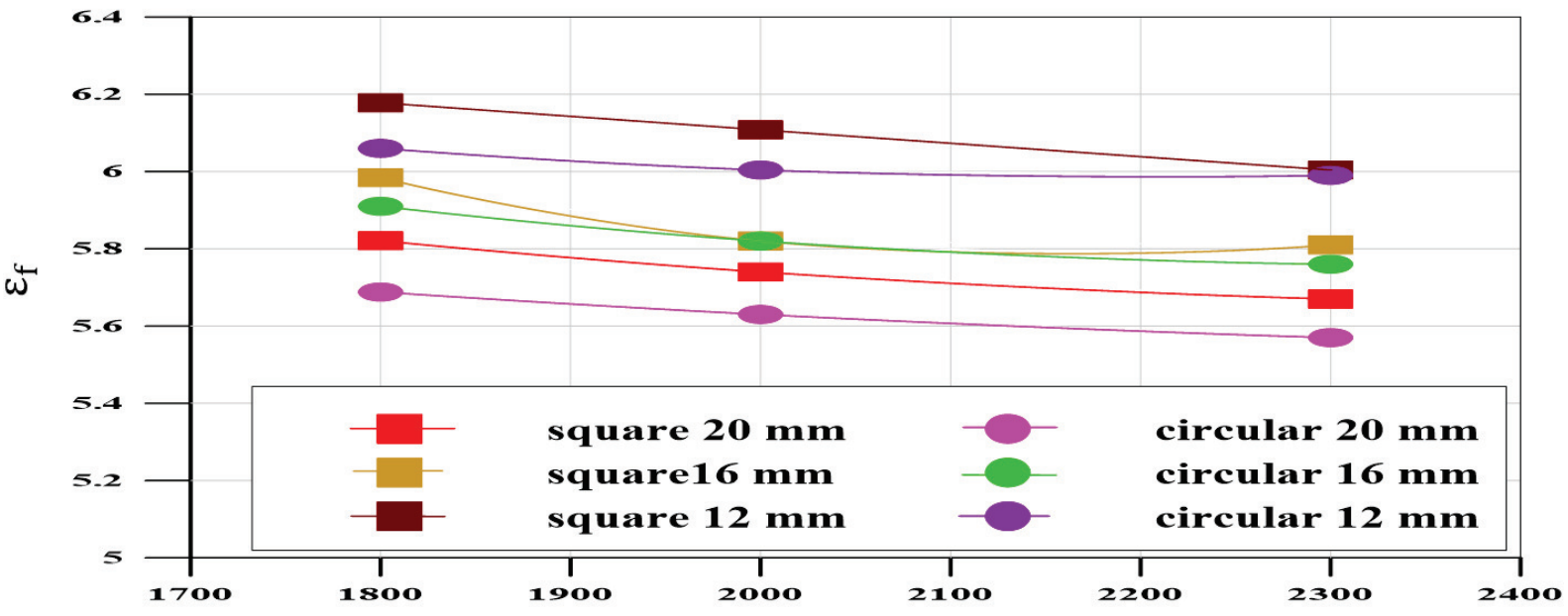

$\operatorname{Re}$

Figure 11.Variation of fin performance with Reynolds number for different size of perforation, $\mathrm{Gr}^{*}=5 \times 10^{8}$, $\mathrm{S}=17 \mathrm{~mm}, \mathrm{H}_{\text {fin }}=60 \mathrm{~mm}, n_{p}=10$.

\section{6-Conclussions:}

A numerical model was used to predict the conjugate heat transfer in horizontal perforated finned channels for forced convection laminar flows. In this study, an attempt is made to improve the performance of horizontal rectangular fin array by removing the less effective portion of the fin surface area in the form of perforations. It is observed that

1-On the observed temperature distribution and calculation by theory, it is expected that observed temperature should affect to the convective heat transfer rate from fins and increases with perforation fins.

2- As area removed from the fin is compensated at the air entry ends of the fin it provides chance to get greater amount of fresh cold air to come in contact with hot fin surfaces then then heat transfer is enhanced by $12 \%$ than solid fins.

3- The heat transfer coefficient of the three types of fins and all wall inclination angles increased with increasing mass flow rate.

4- The effectiveness of fins $\left(\varepsilon_{f}\right)$ value are more than 2 for all type fin arrays. This means that the use of fin arrays leads to an advantage on the basis of heat transfer enhancement. 


\section{7-References:}

[1] Uniyal M. and Joshi K.," Numerical and Experimental Investigation Plane Fin with the Help of Passive Augmentation Method", IOSR Journal of Mechanical and Civil Engineering (IOSR-JMCE), Vol. 12, Issue 6, Ver. II, PP 48-53, Nov. - Dec. 2015.

[2] Webb L. R., "Principles of Enhanced Heat Transfer", Second Edition, Taylor \& Francis Group, New York, 2005.

[3] Mokhtari M., Gerdroodbary B. M., Yeganeh R. and Fallah K., "Numerical study of mixed convection heat transfer of various fin arrangements in a horizontal channel", Engineering Science and Technology, An International Journal 20 ,pp 1106-1114, 2017.

[4] Jassem R. R., "Effect the Form of Perforation on the Heat Transfer in the Perforated Fins", Tikrit University, Iraq, Vol. 4, No. 3, May 2013.

[5] Dhanawade K. H., Sunnapwar V. K. and Dhanawade H. S., "Thermal Analysis of Square and Circular Perforated Fin Arrays by Forced Convection", Navi Mumbai, India, 2014.

[6] Dogan M., and Sivrioglu M., "Experimental and numerical investigation of clearance gap effects on laminar mixed convection heat transfer from fin array in horizontal channel-A conjugate analysis", Applied Thermal Engineering 40, pp.102-113, 2012.

[7] Cengel Y.A., and Ghajar A.J., "Heat and mass transfer fundamental and applications", $7^{\text {th }}$ edition, Johan Wily \& Sons, 2011.

[8] Bergman T. L., Lavine A. S., Incropera F. P. and Dewitt D.P., "Fundamentals of heat and mass transfer", $6^{\text {th }}$ edition, John Wiley\& Sons, 2011. 